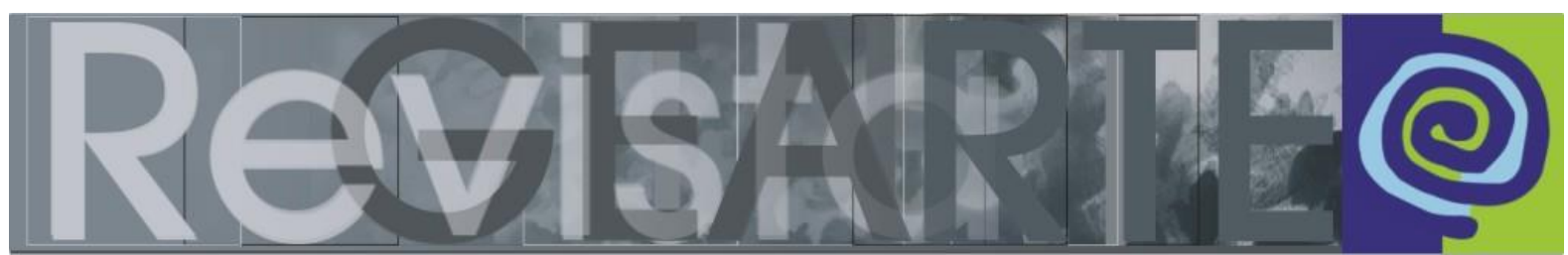

ISSN 2357-9854

\title{
A epistemologia do ensino do desenho
}

\author{
Umbelina Barreto \\ (Universidade Federal do Rio Grande do Sul — UFRGS, Porto Alegre/RS, Brasil)
}

RESUMO - A epistemologia do ensino do desenho - Este artigo aborda a epistemologia do ensino do desenho necessária à complexidade do pensamento contemporâneo e que se apresenta nos currículos de formação superior do artista e do arte-educador. A investigação enfatiza as transformações ocorridas no século XX, relacionadas à emergência do pensamento complexo à luz da Teoria da Autopoiesis de Maturana e Varela, que está inserida em uma concepção sistêmica do conhecimento, e faz uma reflexão sobre as vicissitudes do pensamento contemporâneo, sem prescindir da tradição, principalmente, no que se refere a ética e a estética. $O$ texto tem como referência o Currículo do Curso de Graduação em Artes Visuais da UFRGS, envolvendo a Licenciatura e o Bacharelado e se desenvolve a partir da crítica aos currículos modernistas de formação especialista colocados em paralelo à necessidade da visão generalista que se impõe no pensamento contemporâneo, através da visão inter e transdisciplinar da ciência e da arte. O eixo da pesquisa tem como base a seguinte questão: Como o pensamento contemporâneo perpassa o discurso do ensino do desenho e redefine a epistemologia nos currículos de formação superior do artista e do arteeducador?

\section{PALAVRAS-CHAVE}

Epistemologia. Ensino do desenho. Ensino Superior. Currículo. Pensamento Contemporâneo.

ABSTRACT - The epistemology of teaching of drawing - This paper discusses the epistemology of teaching of drawing required to the complexity of contemporary thought present in the curricula of higher education of the artist and the art teacher. The research emphasizes the transformations that occurred in the 20th century related to the emergence of the complex thought, in the light of the theory of Autopoiesis of Maturana and Varela, that is inserted into a systemic conception of knowledge, and makes a reflection on the vicissitudes of contemporary thought without prescinding the tradition, especially, with respect to ethics and aesthetics. The text has as reference the course curriculum program in Visual Arts UFRGS, involving the Degree and the Bachelor, it develops from the criticism of specialist modernist curricula, placed in parallel to the need of the generalistic vision of contemporary thought, through inter and transdisciplinary vision of science and art. The axis of the research is based on the following question: How the contemporary thought pervades the teaching of drawing and resets the epistemology in the curricula of higher education of the artist and art teacher?

\section{KEYWORDS}

Epistemology. Teaching of Drawing. Higher Education. Curriculum. Contemporary Thought.

\section{Parametrização inicial do objeto de análise}

Pensar na epistemologia do ensino do desenho que se apresenta nos currículos de formação do artista e do arte-educador, relacionando-a ao pensamento contemporâneo, poderá ser, inicialmente, focalizar a mudança de nomenclatura que 
define os componentes curriculares que constituem a área de desenho na formação superior em Artes Visuais.

No ensino superior brasileiro, as reestruturações curriculares têm sido impulsionadas por Diretrizes Curriculares Nacionais definidas por áreas de conhecimento, e homologadas pelo Ministério da Educação, Conselho Nacional de Educação e Câmara de Educação Superior no final do século XX e início do século $\mathrm{XXI}$, conforme publicações disponibilizadas no portal do MEC. Dentro desse quadro de transformações do panorama educacional no Brasil, advindo das regulamentações da Lei de Diretrizes e Bases da Educação Brasileira de 1996, foi implementado um novo currículo do Curso de Graduação em Artes Plásticas na Universidade Federal do Rio Grande do Sul, em 2006 (BARRETO, 2008). Este currículo seguiu a mudança de nomenclatura da área de conhecimento, redefinida como área de Artes Visuais, ampliando o escopo da produção artística, ao abarcar as tecnologias e os meios digitais na construção da linguagem da arte, bem como as didáticas específicas em meios analógicos, digitais, técnicos e/ou tecnológicos, envolvendo a teoria e a prática através de novos procedimentos e processos.

A mudança de nomenclatura da área de conhecimento foi acompanhada por mudanças de nomenclatura de componentes curriculares, definidos como disciplinas, que passaram a constituir os currículos dos Cursos de Licenciatura em Artes Visuais e Bacharelado em Artes Visuais. Entre as novas nomenclaturas, seleciona-se dois componentes curriculares para o desenvolvimento da reflexão neste trabalho, definidos como duas disciplinas da etapa inicial dos cursos de Bacharelado e Licenciatura: Fundamentos da Linguagem Visual I e Fundamentos da Linguagem Visual II, disciplinas de caráter obrigatório, oferecidas, respectivamente, no primeiro e no segundo semestre dos cursos. Estas disciplinas, de certa forma, substituíram alguns componentes da área de desenho do currículo anterior, prioritariamente, as disciplinas denominadas “Introdução ao Desenho" e "Desenho de Observação".

É importante ter o cuidado de salientar que essa mudança de nomenclatura não está restrita a simples troca de componentes curriculares. A mudança envolve uma nova organização curricular que mistura disciplinas e créditos dispondo a possibilidade de realização de percursos curriculares diferenciados, definindo 
diferentes perfis de formação centrados na construção de autonomia e autoorganização do estudante. Poderia se dizer que o atual modelo do currículo, além de ser representado semanticamente por uma estrutura desdobrada em árvore no desenvolvimento do conhecimento, em uma referência originária à árvore de Porfírio (ECO, 2013), abriga, em uma etapa intermediária, uma série de "coleções" compostas de conteúdos diferenciados, os quais, no currículo anterior se estruturavam separadamente em disciplinas de distintas habilitações. Dessa forma, as habilitações que, anteriormente, definiam um perfil de formação especialista, agora têm seus conteúdos totalmente ofertados e podem ser acessados nos planos de estudos dos estudantes a partir de uma etapa curricular intermediária, possibilitando uma definição formativa especialista e/ou uma definição formativa generalista, não se restringindo a substituir uma formação por outra.

É nesse contexto curricular complexo, em que vai sendo tecida uma estrutura curricular mista que modifica a relação entre o docente e o discente ao pressupor a construção de autonomia dos estudantes ao longo da formação, e na qual, inicialmente, interessa pensar a mudança de nomenclatura como uma potência epistemológica, que possibilita o ensino do desenho, em diálogo conjuntivo e disjuntivo com as vicissitudes do pensamento contemporâneo.

\section{O ensino do desenho entre a linguagem visual e o desenho}

Tem-se aqui o interesse de pensar sobre esse espaço que se forma entre a linguagem visual e o desenho, e apresentá-lo como uma possibilidade de se detectar alguns indícios da transformação do discurso do ensino quando se apresenta perpassado pelo pensamento contemporâneo. Essa estratégia de definição de um campo ampliado de pensamento que se desenvolve entre dois polos é significativa, embora saiba-se que, esse espaço só possa vir a ser definido de forma negativa, talvez como uma heterotopia ou um não lugar do desenho, em uma referência aos estudos de Foucault ou aos estudos de Marc Augé (apud SILVANO, 2010), em sua tentativa de inserção do pensamento contemporâneo nas reflexões sobre a antropologia do espaço. 
A heterotopia aqui é vista como um espaço flutuante metaforizado em um barco e o não-lugar como um espaço não identitário. O primeiro se alimentaria das margens de um e de outro, mas, flutuaria eternamente entre os dois. E o segundo se constituiria em desvio, em um deslocamento da forma do desenho caracterizada na e pela nomenclatura utilizada anteriormente, e, também em deslocamento da função da linguagem visual que, diferentemente da linguagem do desenho contemporâneo, tem se voltado, prioritariamente, para a comunicação visual apontada pela nova nomenclatura, em um duplo desvio identitário.

Esse espaço entre as duas nomenclaturas se revela como uma dupla negativa e isso deve-se, justamente, ao fato de que esse espaço está formado por um duplo desvio, da linguagem visual em relação ao desenho contemporâneo, e do desenho em relação à tradição do desenho como uma representação da forma. Nesse sentido, essa amplificação do desvio pode levar à produção de inovadoras observações do mundo, que ultrapassam os sistemas de representação tradicionalmente contidos no desenho, bem como, desviam a primazia da visão que, por definição, está presente na linguagem visual (MAIO, 2011).

Fernanda Maio, diz que o artista contemporâneo passa a ser visto como um fazedor de significados (2011) e já não como produtor de objetos, e verifica-se que, nessa passagem, o artista afasta-se da tradicional relação com 0 artesão, aproximando-se de uma relação com o intelectual.

A partir dessa transformação do artista trazida por Maio (2011) talvez, também se possa dizer que, na contemporaneidade, o foco da visão do desenhador ${ }^{1}$ tenha mudado. Tradicionalmente, o foco do desenhador dá-se em uma relação entre a mão e o olhar, parametrizados pelo pensamento a partir de duas distâncias distintas em relação ao objeto, e agora, ao enfatizar a dialogia presente no desenho contemporâneo, volta-se sobre o próprio pensamento "imprimindo-o" como um outro.

1 A utilização do termo desenhador em substituição ao termo desenhista está sendo utilizada no texto para evidenciar a distinção correspondente à área de Artes Visuais, separando do desenhista industrial, que, na atualidade, também é denominado de designer. 
Percorrer esse não lugar do desenho no ensino do desenho poderá trazer a mão uma espécie de paralaxe do desenho, pois, como alerta o filósofo esloveno Zizek (2008), a visão em paralaxe corresponderia menos a uma mudança no objeto, e mais a uma atitude perante o objeto visto, enfatizando a mudança de posição do observador. $E$ esse pode ser o primeiro indício realmente significativo da epistemologia do ensino do desenho presente nos currículos dos cursos de formação do artista e do arte-educador.

Por outro lado, afluindo com esse primeiro indício, relacionado diretamente a um sujeito, verifica-se o início de uma mudança substancial no que está dado como objeto, pois o desenho começa a redefinir-se como uma linguagem substantiva a partir da segunda metade do século XX. Entretanto, esta redefinição ocorre em um processo que se desenvolve muito lentamente, pois, simultaneamente, tem-se a própria redefinição da arte como uma linguagem. Dessa forma, a arte passa de um enfoque exclusivo no produto, para uma ênfase no processo, podendo ser nomeada como um fazer, e isso torna necessário que se verifique a nomenclatura de linguagem visual relacionada à definição de desenho como um processo.

Ao mesmo tempo em que ocorre essa mudança de foco na arte, tem-se uma crise do pensamento ocidental, iniciada desde o final do século XIX e desdobrada no início do século XX, levando à emergência de novos paradigmas, dos quais emerge o pensamento complexo, que vai sendo constituído por diversas abordagens articuladas de forma sistêmica (VASCONCELLOS, 2002). A partir desses novos referenciais que revolucionam o pensamento científico, sintetizados e desenvolvidos por Khun em seu livro A estrutura das revoluções científicas (1989), surge uma teoria do conhecimento que redimensiona a definição de "ser vivo", articulando essa definição a uma construção autopoiética: Maturana e Varela constroem uma Teoria Biológica do Conhecimento (1984), de onde emerge o conceito de um novo ser humano, que se reitera na autopoiesis de um ser vivo, ao ser definido como um ser que se constitui a si mesmo na linguagem, através de um linguajar que se dá como um fazer/dizer na linguagem em um processo de auto-organização.

Dentre as transformações do pensamento ocidental, entre construções, $\underline{\text { desconstruções e reconstruções do pensamento filosófico, entre fenomenologia, }}$ 
filosofia crítica e filosofia da linguagem têm-se também no século $X X$ a emergência da semiótica que recoloca a semântica no centro da discussão, trazendo teorias do discurso e da interpretação ao lado de teorias da informação e significação. Por um lado, tem-se a semiótica de Pierce, centrada em um sistema de signos construídos em um sistema filosófico voltado para a construção da emergente sociedade industrial do final do século XIX, que enfoca o desenvolvimento da apropriação, leitura e interpretação do mundo unicamente através desse sistema de signos. E, de outra forma, tem-se também uma semiótica voltada para a análise do texto, centrada na construção de um processo infinito de semioses ao definir a realidade como um texto que está dado e que precisa ser ressignificado reiteradamente, trazida por alguns pensadores como um fazer/dizer na linguagem (GREIMAS; LANDOWSKI,1986), ao recuperar a concretude do pensamento no desenvolvimento da construção das ideias, vista anteriormente como o exercício abstrato de um pensamento abstrato.

Entrementes, entre a ciência e a filosofia, o século $X X$ é também o século do salto qualitativo marcado pelo desenvolvimento da tecnologia. $E$, segue-se a isso um desenvolvimento da neurociência, que traz a possibilidade da modificação das estruturas cerebrais através da neuroplasticidade, desencadeada por processos de ensino-aprendizagem que aliam estratégias abstratas com experiências concretas na aquisição de competências que se utilizam de atitudes, habilidades e conhecimentos, permitindo transformar a prática em um novo fazer/dizer, transformando também o mundo em que se vive (COSENZA; GUERRA, 2011).

Depois dessa breve preleção das vicissitudes do pensamento, que estão ocorrendo desde o início do século $\mathrm{XX}$, trazidas no texto de forma seletiva, em diferenças que se articulam, reiteram ou se complementam para evidenciar uma complexidade que se apresenta de forma crescente, mas que configuram certo percurso que envolve as mudanças do sujeito, perpassam o objeto e reiteram novas definições de mudança do sujeito, pode-se voltar a afirmação de Maio (2011). Para a autora, o artista contemporâneo é visto como um fazedor de significados e, nesse retorno, pode-se perceber que, converge com essa redefinição do artista, a colocação em evidência de uma epistemologia do ensino do desenho que poderá corresponder 
a processos investigativos, transformando o discurso do ensino, o qual passa a se misturar com a pesquisa.

Esse novo lugar do ensino do desenho transformado pelo discurso, que, ao se misturar com a pesquisa, passa da escolha do que fazer para a formulação do problema a ser investigado, privilegiando a investigação, emerge na formação superior, no ensino de graduação, apoiado institucionalmente por um estreito diálogo com a ascensão da pesquisa em arte e a consolidação da pós-graduação em arte no Brasil.

Até bem pouco tempo atrás, a pesquisa e a investigação têm sido evidenciadas como uma forma específica dos processos científicos, em contraposição à reflexão como uma especificidade dos processos filosóficos. E, no ensino do desenho, nos currículos de formação superior em artes visuais, tem-se apresentado uma espécie de metodologia dialógica, envolvendo a ciência e, com certa frequência, envolvendo a semiótica científica, que se aproxima da fenomenologia, da filosofia da linguagem e da linguística, ao se propor análises semióticas na construção de processos de significação que articulam o sensível e o inteligível que sempre está presente na apropriação e definição inicial de um problema a ser investigado.

Através de uma nova forma de investigação, em que se misturam a ciência, a filosofia e a arte, poderia também ser definido um novo lugar do ensino de desenho na graduação. E, nesse novo lugar do ensino do desenho, poderia se pensar que o exercício do desenho, inicialmente, passaria a ser, não mais o desenho do mundo, mas o desenho do pensamento, entretanto, seria o desenho de um pensamento que se faz e se diz na linguagem, em um caminho da significação. Um desenho que se constrói na busca de sentido, em uma passagem entre um tema geral e um caminho específico de abordagem, em um percurso que vai se especificando em direção à construção de um novo significado do desenho na especificação de um outro mundo, em que se definiria uma metalinguagem do próprio objeto desenho.

O ensino do desenho, dessa forma, ao evidenciar uma epistemologia sistêmica, também se encaminharia para um caminho impróprio da pesquisa ao enfatizar a simultaneidade do fazer e dizer o próprio fazer como um outro, e do pensar 
e o desenhar o pensamento como um outro. E essa epistemologia do ensino do desenho, relacionada às formas de investigação científica, a partir de uma relação sistêmica, mas percorrendo um caminho impróprio da pesquisa, poderia levar à apropriação de novas formas de fazer, dinamizando o modelo de ensino que se praticava anteriormente.

\section{O ensino do desenho como investigação}

A nomenclatura da disciplina Fundamentos da Linguagem Visual em substituição à disciplina Introdução ao Desenho em si mesma potencializa o fazer na linguagem. Por um lado, multiplicando a capacidade de comunicação, ao se aproximar do visível, e por outro, multiplicando a necessidade de expressão, ao se aproximar do invisível, em um duplo movimento que não se rompe e que acaba por gerar uma potenciação extrema entre o visível e o invisível que se apresenta nos processos artísticos contemporâneos.

Parece paradoxal que, justamente, em uma nomenclatura que explicita a especificidade de uma linguagem relacionada à visibilidade e à construção da visualidade, para ser apropriada conceitualmente em um significado e desenvolvida como leitura em um processo de significação, não prescinda do seu contrário, ou seja, necessite de todo o espaço que ocorre entre o visível e o invisível para que o desenho do pensamento se constitua e se especifique como linguagem.

Por outro lado, é importante lembrar que o processo de visão ocidental tem, tradicionalmente, como fundamento um sistema de representação que pressupõe um observador ideal, a partir de um ponto de vista único e monocular, centralizado, fixo e frontal em relação ao objeto. É somente com a visão modernista, que se desconstrói e se reorganiza o desenho a partir dos elementos visuais pressupostos como uma sintaxe, ao ser disponibilizado um dispositivo mecânico de observação ideal: uma câmera fotográfica, que, por estar agora na mão do observador, pode ser acessada a qualquer momento, e reproduzir e multiplicar o observador ideal, pois parametriza mecanicamente a posição do objeto, deixando-o sempre no centro óptico/matemático ideal, ao mapear completamente as mudanças de posição do observador em relação ao objeto. 
Dondis (1991) em um estreito diálogo com a comunicação visual, ao refletir sobre a sintaxe da linguagem visual traz a necessidade de desenvolvimento de um letramento visual universal, em paralelo ao letramento verbal universal, comparando a invenção do tipo móvel com a invenção da câmera fotográfica. Essa consciência do uso de um dispositivo móvel que reproduz o próprio sistema de observação fundante do olhar ocidental (câmara obscura, conforme David Hockney (2001) é, também, o que liberta o olhar da exatidão matemática do visível.

Santaella corrobora essa relação da câmara obscura com a máquina fotográfica (2010) e a construção do conhecimento do funcionamento do olho humano:

\begin{abstract}
Além de compartilhar essa propriedade dos meios reprodutores, a fotografia introduziu uma novidade, a de ter dado início ao surgimento de máquinas dotadas de certo nível de inteligência, de modo que não é apenas a função memória do cérebro que estas máquinas extrojetam, mas também relativo fator de inteligência produtora, copiadora das faculdades cerebrais. Para os que conhecem a história da fotografia desde a câmara obscura, não é difícil reconhecer que a câmara fotográfica introjetou, materializou em uma máquina o que o desenvolvimento da ciência, desde a Renascença, nos fez conhecer sobre o funcionamento do olho e sobre a fixação do reflexo da luz. (SANTAELLA, 2010, p. 61)
\end{abstract}

O olho em estreita ligação com a mão não precisa mais calcular o mundo para dar visibilidade a um mundo. E é essa liberdade de não se ter um resultado definido cientificamente a priori, e a obrigatoriedade de reproduzi-lo artisticamente a posteriori, que abre um novo campo de investigação para o desenho, e, por sua vez, possibilita que o campo do ensino do desenho transforme o espaço do atelier em um campo investigativo que tende a ampliar os elementos constitutivos da própria linguagem do desenho.

Dessa forma, a linguagem do desenho passa a se estruturar a partir de uma dimensão qualitativa constituída no campo da visibilidade, formado pelo visível e o invisível. Conforme Merleau-Ponty (1984) o mundo é o que vemos e, contudo, temos de aprender a vê-lo, e o filósofo nega que a filosofia possa transformar o mundo em uma coisa dita, como o faria um artista na linguagem. Essa dimensão da linguagem do desenho que tenta apreender a visão desenvolvendo-a no campo da visibilidade, está relacionada a uma estratégia de construção do pensamento que possibilita um 
discurso que, envolvendo o visível e o invisível, integra também a contrariedade, mas sem que o pensamento se rompa na contradição.

No segundo semestre do curso, novamente a disciplina de Fundamentos da Linguagem Visual substitui o desenho, agora não em equivalência à Introdução ao Desenho, mas sim na definição de um procedimento que é a chave desse outro que se constitui ao desenhar: o observador. A disciplina de Desenho de Observação, tradicionalmente, parte, epistemologicamente, de um observador ideal, que por sua vez define padrões de construção de observações também ideais. Nos currículos modernistas o desenho de observação tem se constituído como um processo relacionado à construção de padrões fixos ideais sobre os quais se pode, posteriormente, elaborar uma diversidade de procedimentos de desconstrução, que têm o objetivo de chegar a uma definição abstrata universal ao envolver, principalmente, as abstrações geométricas, e, também as abstrações informais, que surgem em pressuposição às abstrações formais.

Outros dois componentes curriculares tradicionalmente constitutivos da área de desenho presentes nos currículos modernistas são relacionados à representação da figura humana e a apropriação de proporções ideais em um sistema definido matematicamente a partir de um número irracional. Comumente tem-se utilizado o esquema do Homem de Vitrúvio, construído pelo arquiteto Vitrúvio no século I DC e trazido à Renascença ao ser atualizado por Leonardo da Vinci.

Relacionar a representação da figura humana e o desenho de observação traz duas idealizações que se apresentam como regra fixada a priori, e, entretanto, esta regra tem um referencial presente em cada sujeito e no corpo que o constitui, que, necessariamente, passa a ser visto como um desvio da regra.

Fundamentando a linguagem visual, para além da sintaxe dos elementos utilizados que põe o sujeito frente à escolha do que pode ser utilizado, tem-se também o sujeito utilizador, que potencializa a linguagem. E, ao se passar dos sistemas de representação do desenho para a construção de significados e percursos de significação através da linguagem visual, se estará frente a limites que poderão ser dados pelo próprio corpo do sujeito e pela vontade desse sujeito de construir o seu 
próprio percurso. Nesse sentido, ao se reiterar a pesquisa da linguagem visual na estrutura curricular possibilita-se que, nesse caminho, o estudante possa se voltar sobre a sua forma de "deformar" ou se "desviar" do mundo ideal da representação, movimentando um padrão que, anteriormente, era dado como fixo.

Também na história da arte tem-se esta relação entre a norma da construção da imagem ideal e a norma da construção da imagem deformada pelo vivido. Entre a visão de Leonardo Da Vinci e a visão de Albrecht Dürer, tem-se um espaço entre o artista que olha e busca a forma na precisão do ideal e o artista que olha e busca a deformação do vivido, na imprecisão do que não é totalmente apreendido. DidiHuberman (2009) confirma a visão ideal do primeiro ao se referir à metáfora de uma cebola utilizada por Da Vinci para descrever um corte de uma cabeça humana, e a visão distorcida e desestabilizante do segundo, que menciona "revirar (uma cabeça) sobre o fundamento", e busca pontos de vista impossíveis, trazendo visões estranhas e paradoxais, que para Didi-Huberman abre o espaço de nossa visibilidade como uma complexidade móvel metaforizada em uma "uma linha caracol".

\section{O ensino do desenho como a visão em paralaxe do desenho}

Trazer o ensino do desenho como o outro do desenho é também a evidência desta nova identidade contemporânea do artista que se coloca mais próximo do intelectual do que do artesão, em um deslocamento da metodologia para a semântica do ensino. É forjar os limites da linguagem entre o fazer do desenhador e o dizer do ensino do desenho, fazendo com que ambos se constituam na linguagem como esse outro do desenho. É trabalhar a linguagem visual a partir de seus fundamentos e pressupostos epistemológicos, desenvolvendo-a no campo da visibilidade e da visualidade como uma forma de ensino de desenho ao ampliar a visão do desenho, inserindo-o em um novo paradigma que o transforma em experiência.

Para Maturana (2001), o histórico de interações do desenhador e do professor de desenho, na formação do artista e do arte-educador, é condição suficiente para borrar os limites do discurso entre ambos, e daí emergir um novo discurso do ensino do desenho e novas tipologias de desenhadores contemporâneos. Pode-se ver como o conceito de desenho contemporâneo redefine o conceito de ensino de desenho, e 
também como o conceito de ensino de desenho contemporâneo redefine o conceito de desenho. A questão é que ambos são atravessados por um pensamento contemporâneo, em um paradigma complexo em que se instala uma visão sistêmica do mundo, definindo uma epistemologia também sistêmica.

Muito se tem refletido sobre o desenho e o ato de desenhar relacionados à forma de organizar o pensamento e à visibilidade definidora do conhecer. Também muito se tem refletido sobre as possibilidades de leitura e a construção da visualidade no que é tornado visível pelo outro. Mas, como se cruzam a visualidade e a visibilidade na emergência de uma nova epistemologia no ensino do desenho?

Trazer o letramento visual como ensino de desenho no curso de formação do artista e do arte-educador pode ser instaurar o conceito de desenho na complexidade do mundo atual de forma a tornar significativas as diferentes concepções e paradigmas de desenho que o estudante se depara ao longo de sua formação. É claro que aqui já se está pressupondo também a convergência das consequências da mudança advinda da relação de construção de autonomia do estudante de arte, que vai escolhendo as deformações que definem a sua "própria linha caracol".

Pensar como se pode saber sobre o saber do desenho para se chegar ao discurso do ensino do desenho, transformado pelo discurso contemporâneo, tem sido desde o início o que se movimenta nesse texto. Mas, verifica-se que, o lugar que se quer mapear tem se mostrado somente em deslocamentos e desvios. Nesse viés, 0 ensino do desenho passa a ser perseguido em um caminho que se desenvolve a partir de uma referência externa, em que se problematizam uma diversidade de formas de captura do mundo, ao passar pela captura do próprio desenho, em uma busca que se constitui na linguagem e também se constitui como linguagem em um processo que se dá sempre em recursividade.

\section{De que conhecimento se está tentando falar nesse texto?}

Este texto iniciou com uma parametrização e a definição de um deslocamento. Poderia se pensar que fazer uma pesquisa sobre a epistemologia do ensino do desenho seja, de alguma forma, um deslocamento. Gregory Bateson (1979) enfatizou 
o contraste e o contexto como a diferença que faz a diferença, e, buscar, à guisa de conclusão, a amplificação do deslocamento que foi utilizado no texto, poderá significar uma aproximação desse conceito de diferença trazido por Bateson.

Ou, poderá levar a afirmar, como Bateson (1979), que "o mapa não é o território", e, dessa forma, também afirmar que os diferentes aspectos de um fenômeno e as diferentes representações trazidas por diferentes observadores é que são os constituintes do conhecimento, móveis e flutuantes, e que, também a ação de conhecer é complexa envolvendo uma diversidade de caminhos, incluindo o próprio retorno do observador sobre a sua própria observação, conforme Morin (1983).

Esse retorno do observador sobre si mesmo também foi trazido no texto como uma espécie de retroação, envolvendo o desenhador e o ensino do desenho, transformando a concepção de desenho do docente e do discente, e, possibilitando que ambos definam seus próprios mapas mentais na complexidade do pensamento contemporâneo, tendo por princípio o ensino do desenho presente nos currículos de formação do artista e do arte-educador.

Verifica-se que o ensino do desenho está sendo abordado em uma espécie de acordo e desacordo simultaneamente tanto com o objeto como com o sujeito, pois multiplica um discurso que envolve os dois. A justificativa é, a princípio, a variabilidade dos focos e os princípios relacionados ao conhecimento que emergiram do caminho que aqui se encetou. A opção realizada no texto foi de focalizar o que está mais próximo, mas que, depois de certa idade, é justamente o que não se consegue delinear se não se usar uma lente multifocal. Entretanto, é essa lente multifocal que possibilita uma ampliação do foco, multiplicando-o e distribuindo os focos em pelo menos três campos da visão, que correspondem ao desenhador, ao desenho e ao ensino do desenho, e que estão completamente interligados.

Ainda com Bateson (1986) afirma-se o óbvio, dizendo que o conhecimento sobre o objeto desenho não é o objeto desenho, e também que o conhecimento sobre o objeto desenho não é o sujeito desenhador. Tampouco o conhecimento do objeto desenho é o ensino do desenho, embora possa se dizer que o ensino do desenho tem por princípio uma relação dialógica tanto com o desenho, como com o desenhador. $\mathrm{E}$, 
não é só isso, pois esta relação dialógica multiplica-se no tempo e no espaço, pressupondo a tradição, bem como a contemporaneidade de um e de outro.

Por fim, restaria ainda questionar como está sendo reconstruído o pensamento contemporâneo no ensino do desenho. E como esta reconstrução possibilita que no processo do desenho se identifiquem alguns pressupostos epistemológicos, tais como a complexidade, a multifocalidade, e a flutuação trazidas neste texto. Sem descartar ou anular paradigmas tradicionais ao definir novos paradigmas, de forma aberta e acumulativa, as mudanças no ensino do desenho estão em estreita ligação com a emergência do desenho como uma linguagem substantiva, definida como um corpo dialógico e complexo, em que, mesmo em processos negativos de apagamento da visão, abarca o visível e o invisível ao dialogar com a visibilidade e a visualidade do desenho e do mundo.

\section{Referências}

BARRETO, Umbelina Maria Duarte. Espiando pelo buraco da fechadura. O conhecimento de Artes Visuais em nova chave. Porto Alegre: UFRGS, 2008. 224 f. Tese (Doutorado em Educação) Universidade Federal do Rio Grande do Sul. Faculdade de Educação. Programa de Pós-Graduação em Educação, Porto Alegre, 2008.

BATESON, Gregory. Mente e natureza. Rio de Janeiro: Ed. Francisco Alves, 1986.

BATESON, Gregory. Uma ecologia da mente (on gregory bateson's thought). Vídeo de Nora Bateson. Disponível em: https://www.youtube.com/watch?v=Tfc39iHUKmQ\&nohtml5=False Acesso em: 07 abr. 2016.

COSENZA, R. M.; GUERRA, L. B. Neurociência e educação: como o cérebro aprende. Porto Alegre: Artmed, 2011. $151 \mathrm{p}$.

DIDI-HUBERMAN, Georges. Ser crâneo. Lugar, contato, pensamento, escultura. Belo Horizonte: Editora C/ Arte, 2009.

DONDIS, Donis A. Sintaxe da linguagem visual. São Paulo: Martins Fontes, 1991.

ECO, Umberto. Da árvore ao labirinto. Rio de Janeiro: Editora Record Ltda., 2013.

GREIMAS, Algirdas Julian; LANDOWSKI, Eric. Análise do discurso em Ciências Sociais. São Paulo: Global, 1986.

HOCKNEY, David. O conhecimento secreto. São Paulo: Cosac \& Naify, 2001.

MAIO, Fernanda. A encenação da arte. Leiria: Textiverso Ltda., 2011.

MATURANA, Humberto; VARELA, Francisco. El Árbol Del Conocimiento. Santiago: Universitaria, 1984.

MATURANA, Humberto. Cognição, ciência e vida cotidiana. Belo Horizonte: Ed. UFMG, 2001.

MERLEAU-PONTY, Maurice. O visível e o invisível. São Paulo: Perspectiva, 1984.

MORIN, Edgar. Problema epistemológico da complexidade. Portugal: Europa-América, 1983.

SANTAELLA, Lucia. A ecologia pluralista da comunicação: conectividade, mobilidade, ubiquidade. São Paulo: Paulus, 2010. 400 p. 
SILVANO, Filomena. Antropologia do espaço. Lisboa: Assírio \& Alvim, 2010.

VASCONCELLOS, Maria José Esteves. Pensamento sistêmico. Campinas: Papirus, 2002.

ZIZEK, Slavoj. A visão em paralaxe. São Paulo: Boitempo, 2008.

\section{Umbelina Barreto}

Graduação em Artes Plásticas/ Habilitação Desenho e Pintura - UFRGS (1978), Mestrado em Filosofia - PUCRS (1994) e Doutorado em Educação - UFRGS (2008). Professora Associada, nível I, do Instituto de Artes da UFRGS. Membro do Grupo de Pesquisa em Educação e Arte (GEARTE) - PPGEDU da Faculdade de Educação da UFRGS. Possui experiência na área de Artes Visuais com ênfase em Desenho e Pintura, e tem realizado produção regular em poéticas visuais, além de exposições no Brasil e no Exterior. Na pesquisa tem atuado, principalmente, nos seguintes temas: Ensino e Pesquisa da Linguagem do Desenho e Ensino e Pesquisa em Semiótica Discursiva. Tem realizado pesquisas na área de Semiótica, Filosofia da Arte e Epistemologia da Arte.

E-mail: umbelina.barreto@ufrgs.br

Currículo: http://lattes.cnpq.br/5596431631660931 